\title{
Del sujeto y la repetición en la educación al reconocimiento ético como acto educativo
}

\section{From subject and Repetition in Education to Ethical Recognition as an Educational Act}

\author{
Facundo Giuliano ${ }^{1}$ \\ CONICET (Argentina)
}

Recibido: 11-04-2017

Aprobado: 23-08-2017

\section{Resumen}

Las páginas que componen el presente artículo se plantean como una instancia de reflexión filosófica en torno de tres cuestiones: a) la caracterización de la escena fundadora de la educación latinoamericana como contenido históricamente reprimido que retorna de diferentes modos en la educación contemporánea mediante una repetición sintomática de lo mismo; b) la problematización del sujeto (pedagógico) que encarna esa repetición en medio de la tensión entre el Sujeto que hay y el sujeto (colectivo) que adviene o acontece como novedad radical; c) la búsqueda de formas de re-existencia pedagógica que partan de una igualdad radical para plantear el acto educativo, concebido este último como un gesto que subvierte el principio estructurante de su propio campo de (im)posibilidades. En este sentido, se explicitarán algunas puntuaciones para hacer (otra) escuela desde posiciones que implicarían a un maestro popular e igualador como podrían ser los sugeridos por Simón Rodriguez y Jacques Rancière.

Palabras-clave: filosofía de la educación, sujeto, alteridad, subjetividad, ética, pedagogía.

\footnotetext{
${ }^{1}$ (giulianofacundo@gmail.com). Licenciado en Ciencias de la Educación por la Facultad de Filosofía y Letras de la Universidad de Buenos Aires con estudios de posgrado en Filosofía, Psicoanálisis y Literatura. Becario doctoral del Consejo Nacional de Investigaciones Científicas y Técnicas (CONICET, Argentina), tema: "Crítica de la razón evaluadora: implicancias ético-políticas en educación". Investigador de la Universidad de Buenos Aires: miembro del Proyecto UBACyT "Sujeto pedagógico: identidad, diferencia y alteridad. Aportes desde la Filosofía de la Educación" (IICE-UBA) y Director del proyecto PRIES “Alteridad y discursos tecno-educativos. Una deconstrucción de la racionalidad técnica en educación en clave ética-política" (FFyL-UBA). Docente adscripto a la cátedra de Filosofía de la Educación de la carrera Ciencias de la Educación (FFyL-UBA). Autor de Rebeliones éticas, palabras comunes. Conversaciones (filosóficas, politicas, educativas) con Judith Butler, Raúl Fornet-Betancourt, Walter Mignolo, Jacques Rancière, Slavoj Žižek (Miño y Dávila Editores, 2017).
} 


\begin{abstract}
The pages that compose this article are proposed as an instance of philosophical reflection around three issues: a) the characterization of the founding scene of Latin American education as a historically repressed content that returns in different ways in contemporary education through a symptomatic repetition of the same; b) the problematization of the (pedagogical) subject that embodies this repetition in the middle of the tension between the subject that exists and the (collective) subject that comes as a radical novelty; c) the search for forms of pedagogical reexistence that start from a radical equality to postulate the educational act, the latter conceived as a gesture that subverts the structuring principle of its own field of (im)possibilities. In this sense, some scores will be made explicit to make (another) school from positions that would imply a popular and equalizer teacher such as those suggested by Simón Rodriguez and Jacques Rancière.
\end{abstract}

Key-words: philosophy of education, subject, alterity, subjectivity, ethics, pedagogy.

\title{
El eterno retorno de lo reprimido en la educación: de cuando la pedagogía se impuso como un Requerimiento que manda y ordena...
}

Puiggrós (1996) sostiene que el mayor pecado de los historiadores ha sido ocultar la escena fundadora de la educación latinoamericana ${ }^{2}$, aquella que involucra a Juan López de Palacios Rubios (consejero de Fernando el Católico) al redactar en 1514 lo que conocemos como El Requerimiento. Este se trataba de una explicación sumaria de la doctrina cristiana y la justificación del derecho de los cristianos a sujetar a los indígenas a su poder. Su enunciación (de marcado carácter performativo), dice Puiggrós, equivalía a la fundación de una relación pedagógica que estableció la matriz de la desigualdad como ley

\footnotetext{
2 Para no reducir la referencia a América Latina a una delimitación meramente espacial u ontológica/idiomática en su vertiente española o portuguesa predominante, se nos torna fundamental la orientación introducida por Walter Mignolo (2007) cuando, en su libro La Idea de América Latina, busca separar el nombre del subcontinente de la imagen cartográfica que tenemos de él, ya que aborda la cuestión dejando en claro que no se trata de una entidad denominada "América Latina", sino de una idea que se construyó sobre cimientos imperiales/coloniales, cuya excavación se hace necesaria para desentrañar la historia colonial que dio forma a tal denominación. Por lo tanto, excavar la «idea de América Latina» implica comprender cómo nació Occidente y cómo se fundó el orden mundial moderno a partir de la expansión colonial europea y los relatos de esa expansión que dieron lugar a invenciones como la noción misma de América (Mignolo 2007). De aquí que no podamos pensar en la "latinidad" sin pensar en la subordinación, el borramiento o degradación de otras formas de estar en el mundo como cuestión inherente a la historia, el significado y las consecuencias de la idea de América Latina.
} 
y los términos de equivalencia de los sujetos: los españoles identificaron a los indígenas por su ignorancia de la lengua y la religión colonizadora (y no por el reconocimiento ético de sus propias tradiciones y cosmovisiones), los señalaron como no educados y los sospecharon incapaces de educación ${ }^{3}$. Ese vínculo o relación pedagógica no es genéricamente entre dominador y dominado, no se trata de la simple reproducción de una escena del pasado, sino de la creación de una forma particular de dominación que -sostenemos- se repite y repetirá como eterno retorno de lo reprimido cada vez que en un espacio educativo, en el marco de una relación desigualitaria, existe un requerimiento que ordena y manda a unos sobre otros. Por ello, habrá que bucear en la profundidad del síntoma que insiste, persiste y frecuentemente deviene escena repetida.

Dicho requerimiento, que manda y ordena, coloniza el espacio (pensemos aquí el pedagógico en particular) fundando sus relaciones en una desigualdad que clama para sí entendimiento por parte del otro -sobre esa relación y nueva forma de estar- que pone en su centro la majestuosidad del Amo Institucional, reclamando para sí un reconocimiento (no-ético) que se presenta siempre en primera persona. Supone un artificio temporal que indica un tiempo "justo" en el que esta situación -y todo el contenido que implica- debería introyectarse o "aprenderse", de modo tal que el consentimiento de este contexto se cristalice en la "donación" que los Otros tendrían que realizar para con el Uno (o colonizador). De hacerlo bien, es decir, además de lo mencionado, cumplir con las obligaciones impuestas, se propone alguna "experiencia de libertad sin servidumbre" con el "privilegio" de la excepción. Caso contrario, de no hacerlo así, de no cumplir con las obligaciones, el castigo será el mal o el daño a realizar a quienes se resistan o contradigan la majestuosidad del Amo Institucional o Señor Pedagógico, y esos males o castigos serán su propia responsabilidad como merecidas por su cargo de culpa.

Un planteo semejante (inspirado en el texto de El Requerimiento, cuyo nombre completo se conoce como Notificación y requerimiento que se ha dado de hacer a los moradores de las islas en tierra firme del mar océano que aún no están sujetos a Nuestro Señor), pone de manifiesto la imposición

\footnotetext{
${ }^{3}$ En resumen, El Requerimiento se inscribe en la coyuntura de una célebre cuestión ontológica: la humanidad o no de los pueblos originarios. A partir del momento en que un papa romano afirma que esos individuos también son seres humanos, la conclusión lógica de los colonizadores fue que debían ser evangelizados -mediante lo que conoceríamos como misiones jesuíticas-. Para esto era necesario que fueran educados o, al menos, alfabetizados. La nueva orden de los Jesuitas, precisamente para los fines de evangelización de todas las colonias de más allá de las metrópolis europeas, se dirige hacia todos los continentes pero especialmente para América Latina. Aquí el proceso educativo habrá de encuadrarse con los objetivos colonialistas portugueses y españoles. Así, la educación va a asumir el papel ideologizante de garantizar y favorecer los intereses de una colonización predatoria. Nadie mejor que los misioneros para subyugar y apaciguar a los primeros dueños de las tierras para que las entreguen en el nombre de Dios. Así fue que la educación jesuítica, mientras evangelizaba, servía a los intereses colonialistas e iba engendrando un proceso educativo de manipulación y control sociocultural.
} 
de una autoridad y su respectiva obediencia o sumisión a la misma en medio de una escena prominentemente pedagógica. Bien podría funcionar como traducción pedagógica de un síntoma que se repite en nuestros días, aunque, como sabemos, un síntoma puede tener diferentes anudamientos en un sujeto. Tal como afirma Žižek (2009) tomando a Lacan, el síntoma se nos presenta primero como una huella, que nunca será más que una huella, y que siempre permanece incomprendida hasta el momento en que el análisis haya avanzado suficientemente, y hasta el momento en que hayamos comprendido su sentido. El análisis se concibe, así pues, como una simbolización, una integración simbólica de huellas imaginarias (en apariencia) sin sentido. Ahora bien, el análisis del síntoma y su anudamiento respectivo siempre es en relación a un sujeto en medio de una escena fantasmática que se repite. Ya habiendo visto cierta caracterización de la escena, será importante concentrarnos en la cuestión del sujeto que la habita, la repite y, por ello, la hace (im)posible.

\section{La cuestión del sujeto (pedagógico) o el sujeto de una cuestión (pedagógica)}

Es cierto, la educación es una práctica formadora y transformadora de sujetos, que se produce en múltiples modos y espacios de la compleja trama social (Rodriguez 2013). Las situaciones educativas coadyuvan a la constitución, producción o reproducción y cambio del sujeto. Tal como lo expresa Puiggrós (2006), en el sistema educativo moderno, siempre se trata de sujetos (educadores) que intentan incidir en otros sujetos (educandos) para lograr que se transformen: a esta mediación, esta relación entre educador y educando, producto de la vinculación (pedagógica) entre los complejos sujetos sociales que ingresan a las situaciones educativas, le llamará sujeto pedagógico. De aquí sostiene que toda pedagogía define su sujeto, cada una determina los elementos y las normas que lo ordenan como conjunto significante, cuya función es mediar entre los sujetos políticos y sociales actuantes en la sociedad.

En cierta relación, pero desde una perspectiva de análisis política del discurso, se mira a la educación como una práctica de interpelación constituyente de sujetos: siguiendo a Buenfil Burgos (1996), interpelación es, en este contexto, el acto mediante el cual se nombra a un sujeto; es decir, la operación discursiva mediante la cual se propone un modelo de identificación a los agentes sociales a los cuales se pretende invitar a constituirse en sujetos de un discurso. Aquí entran en juego distintas modalidades discursivas (lingüística, gestual, ritual, arquitectónica, de vestimenta, etc.) y unidades significativas de mayor o menor complejidad (desde un enunciado simple o una combinación de imagen y enunciados hasta una configuración extensiva de 
enunciados, imágenes, gestos, sonidos, etc.). Ahora bien, por Laclau y Mouffe (2010: 156) sabemos que el sujeto no es una entidad quieta o inmóvil, igual a sí misma o esencial, sino que, al participar del carácter abierto de todo discurso, participa de diferentes posiciones (de sujeto) que son posiciones discursivas y que no logra fijarlas totalmente en un sistema cerrado de diferencias. Entonces, siguiendo este planteo, la especificidad de la categoría de sujeto no puede establecerse ni a través de la absolutización de una dispersión de "posiciones de sujeto", ni a través de la unificación igualmente absolutista en torno a un "sujeto trascendental".

La categoría de sujeto está penetrada por el mismo carácter polisémico, ambiguo e incompleto que la sobredeterminación acuerda a toda identidad discursiva. Por esto mismo, el momento de cierre de una totalidad discursiva, que no es dado al nivel "objetivo" de dicha totalidad, tampoco puede ser dado al nivel de un sujeto que es "fuente de sentido", ya que la subjetividad del agente está penetrada por la misma precariedad y ausencia de sutura que cualquier otro punto de la totalidad discursiva de la que es parte. "Objetivismo" y "subjetivismo"; "totalismo" e "individualismo" son expresiones simétricas del deseo de una plenitud que es permanentemente diferida. Por esa misma falta de sutura última es por lo que tampoco la dispersión de las posiciones de sujeto constituye una solución: por el mismo hecho de que ninguna de ellas logra consolidarse finalmente como posición separada, hay un juego de sobredeterminación entre las mismas que reintroduce el horizonte de una totalidad imposible. Es este juego el que hace posible la articulación hegemónica (Laclau y Mouffe 2010: 163-164).

Pero, a diferencia de Buenfil Burgos y profundizando la postura de Laclau y Mouffe, para Butler resulta claro que cualquier esfuerzo por ordenar al sujeto a través de una captura performativa por la cual el sujeto se convierte en sinónimo del nombre por el cual es llamado está condenado a fracasar:

Podríamos decir que cada sujeto tiene una complejidad que ningún nombre puede capturar, $y$ así refutaríamos cierta forma de nominalismo. O podríamos decir que hay en cada sujeto algo que no puede ser nombrado, por complicado $y$ variado que llegue a ser el proceso de nombrar (...). O podemos pensar un poco más atentamente acerca del nombre, es decir, al servicio de qué tipo de aparato regulador funciona, si funciona solo o no, si requiere para "funcionar" una repetición que introduzca la posibilidad del fracaso en cada intervalo. Es importante recordar, con todo, que la interpelación no siempre opera a través del nombre: este silencio podría ser destinado a ti. Y el medio discursivo por el cual los sujetos son puestos en orden falla no sólo debido a un algo extradiscursivo que resiste la asimilación al discurso, sino porque el discurso tiene muchos más objetivos y efectos que aquellos efectivamente pretendidos por sus usuarios. Como instrumento de efectos no intencionales, el discurso puede producir la 
posibilidad de identidades que pretende focluir. De hecho, la articulación de la forclusión es el primer momento de su potencial anulación, ya que puede ser rearticulada y contrariada una vez lanzada en una trayectoria discursiva, desamarrada de las intenciones que la animan (Butler 2011: 162-163).

Cuando pensamos, entonces, la cuestión del sujeto pedagógico o el sujeto de una cuestión pedagógica, no se tratará de pensar en una mera ontología, sustancia o esencia identitaria. Sino, antes bien, se trata de pensar la mediación de una inquietud que, necesariamente, habrá que plantear en términos éticopolíticos por tratarse de una práctica de interpelación que intenta nombrar (de manera siempre fallida) aquello que se escapa de la infatuación identificatoria o cambia de posición por su alteritaria polisemia, ambigüedad o incompletud radical que lo tornan ineludiblemente frágil. Desde una perspectiva lacaniana, podría pensarse como sujeto de lo Real, esto es, como sujeto de un cierto límite que puede rebasarse, dejarlo atrás, pero que no podemos alcanzar. Siguiendo a Žižek (2009), podemos inscribir o circundar el lugar vacío del sujeto a través del fracaso de la simbolización de éste, porque el sujeto no es sino el punto fallido del proceso de su representación simbólica. En suma, lejos de aparecer como el resultado de la interpelación, el sujeto (pedagógico) aparece sólo cuando y en la medida en que la interpelación finalmente fracasa: el sujeto no sólo nunca se reconoce a sí mismo plenamente en la llamada interpeladora, su resistencia a la interpelación (a la identidad simbólica provista por la interpelación) es el sujeto (Žižek 2011: 124).

Por otra parte, desde una filosofía de la educación en clave Badiou,Alejandro Cerletti (2008) concibe al sujeto como la construcción (individual o colectiva) que unifica los efectos de un acontecimiento $y$ esta sostenida en la decisión de admitir, como ruptura efectiva con lo que hay, aquello que el acontecimiento altera. En este sentido, la existencia de un sujeto está esencialmente ligada a la alteración de un estado de normalidad, lo cual quiere decir que no hay un sujeto general que trascienda o preexista a las situaciones sino que hay sujeto de o en situación que se constituye a partir de y en un acontecimiento. A partir de este planteo, distingue entre sujeto-objetivo de la educación (que refiere al sujeto que la educación produce o al que da lugar y que adquiere un sentido objetivo) $^{4}$ y sujeto-subjetivo (que refiere a una construcción, una consecuencia

${ }^{4}$ La constitución de subjetividad, en esta perspectiva, consiste en la progresiva asimilación de los saberes y las normas dominantes. Posee un carácter subordinado - o sujetado- a las condiciones específicas de su aparición en la situación educativa y su metaestructura estatal. En efecto, se constituye amoldándose a los saberes y las practicas instituidos, siendo un elemento más del funcionamiento objetivo de una estructura de repetición y a partir de su identificación -más o menos intensa-con los modelos dominantes, es decir, por su incorporación personal a la secuencia de lo que hay. Los sujetosobjetivos están tramados por los supuestos de la situación educativa; son esencialmente espectadores del mundo, al que se van anexando de a poco, y consumidores de lo que ese mundo ofrece. Se plantean los problemas del sentido común o los que los saberes dominantes autorizan a plantear, y las respuestas que se dan, o les dan, son las del sentido común o las que anticipan los saberes dominantes. Dichos sujetos aprenden cuando se ubican en la continuidad que las instituciones y sus saberes preparan para 
o una obra del sujeto que involucra primordialmente un sentido subjetivo $)^{5}$. Cerletti se desmarca de las miradas dominantes que identifican al sujeto de la educación con una individualidad determinable a partir del aprendizaje, de las teorías o prácticas educativas, del derecho o la formación moral, de la psicología o el psicoanálisis. Por el contrario, concibe al sujeto educativo como un sujeto colectivo: esto significa que lo que se constituye en sujeto es el triángulo pedagógico que se produce en una recomposición de la relación educativa a partir de una novedad. Asimismo, es colectivo porque hubiera sido otra la recomposición (o no hubiera ocurrido nada) si hubieran sido otros los participantes y otro el contexto de su efectuación. Es decir, la posibilidad de que exista un sujeto educativo depende de una particular combinación de circunstancias y decisiones en una situación y no de una práctica pedagógica instituida o una política educativa. Constituirse en sujeto es más una excepción que un hábito para alguien (uno o varios) que afronta el desafío de tomar decisiones allí donde los saberes estatuidos no dicen qué hacer o son inconsistentes, lo cual hace del acto educativo un pensar-hacer conjunto (que alude y quiebra o agujerea un saber) en tanto verdad que es diferente de una razón o un entendimiento que aspira a conocer. Quien piensa es, en verdad, el sujeto colectivo en una singularidad. Pero, ¿qué sucede cuando la subjetividad queda merced a la normalidad en educación?

La constitución de la subjetividad en los procesos educativos normales se inscribe en la continuidad del estado de las cosas, ya que el Estado da un lugar a los sujetos, esto es, a su libertad individual (su autonomía dentro de un marco sociopolítico regulado -actualmente, en la estructura del capitalismo contemporáneo-). El Estado integra así a sus miembros, fortaleciendo el lazo social que dicho estado conserva. Si los estados de normalidad se mantienen, quiere decir que todo ocurre de acuerdo a la pre-visibilidad del sistema (por ejemplo, del sistema educativo). Cada disrupción o alteración puede ser interpretada desde los saberes establecidos y, con los recursos normales instituidos, resuelta o disuelta (...) en estos casos de continuidad en la normalidad, no habría, en sentido estricto, ningún sujeto, ya que no se puede sostener, también en sentido estricto, ninguna singularidad. Lo que las situaciones educativas presentan, el estado lo representa desde su ley de unidad (Cerletti 2008: 76-77).

él. Pasan entonces a ocupar un lugar determinado: son presentados por y en una situación educativa y son representados por el estado. Su subjetivación educativa es un proceso continuo de individuación dentro de la normalidad del estado de las cosas (Cerletti 2008: 77-82).

${ }^{5}$ En este caso, la constitución de subjetividad está marcada por el estatuto de una novedad. El sujeto-subjetivo de la educación establece una particular relación con lo que hay a partir de ciertas decisiones y lo que ocurre con ellas. Es decir, se constituirá a partir de algún tipo de diferenciación con lo que hay y de apropiación de los saberes que la institución pone en juego. Aprende a partir de un acto de disrupción que, al mismo tiempo, le es constitutivo. 
Así serán sujetos-objetos o sujetos-objetivos ya que, de alguna manera, son producidos o efecto, resultado o consecuencia de la acción educativa y no hay ningún cambio real sino, a lo sumo, modificaciones acumulativas. De aquí que, para dicho planteo, el sujeto-objetivo es homologable a lo que se ha llamado tradicionalmente sujeto pedagógico. En cambio, diferente es el sujeto en la educación que se corresponde con la existencia de acontecimientos, o los efectos de ellos, en el seno de la institucionalidad educativa porque:

La subjetivación del acontecimiento implica que, frente a lo que ha desbordado o interrumpido la situación, se ha pensado-actuado de una manera inédita respecto de lo que se sabía o esperaba de la situación. Por este motivo, Badiou llama pensamiento directamente al sujeto, en tanto se constituye en un proceso transversal a la totalidad de los saberes disponibles (...) Esta posibilidad local de un pensamiento-sujeto inaugura el despliegue de una serie de consecuencias que, para no quedar inmediatamente subsumidas en la situación de origen, deberán ser coherentes con la novedad que introduce el acontecimiento. El desafío es, entonces, llevar adelante el cambio, constituyéndose en él. Bajo los efectos de un acontecimiento, alumnos y maestros son algo más que individuos librados al juego institucional de un establecimiento educativo. Se sitúan de otra forma frente a lo que es esperable. Esto supone decisiones singulares, y el trayecto programado de la enseñanza inicia un recorrido diferente por las consecuencias de esas decisiones. En este sentido, no se trata de un sujeto individual (tal o cual alumno, ese profesor, etc.), sino que implica una especial conjunción de multiplicidades: alumnos, maestros o profesores, saberes, lugares, tiempos. Se trata más bien, entonces, de un sujeto colectivo (Cerletti 2008: 102).

Hay elementos anteriores que se mantendrán operativos en la situación, pero lo que se presenta portará, a su vez, elementos novedosos (los que no son ni pueden ser representados) que harán que las consecuencias de lo que está sucediendo sean inéditas frente a las situaciones normales. Con este planteo, entonces, hemos puesto de manifiesto algunas pistas que buscan problematizar el sujeto pedagógico y, así también, abrir horizontes para seguir pensando el sujeto en la educación. Pero, luego del recorrido planteado, no podemos dejar de explorar el interrogante acerca de aquello que se reconoce como Sujeto y aquello que no o, en otras palabras, la brecha de imposible sutura que caracteriza el hiato entre el reconocido Sujeto que hay y el desconocido sujeto que (ad) viene. De aquí que, sin ánimos de caer en un marco binario ${ }^{6}$ que reduzca la

\footnotetext{
${ }^{6}$ Para Butler (2010: 200-201) el marco binario presupone conocer todo lo que se necesita saber antes de cualquier investigación real sobre una realidad cultural siempre compleja. Es una forma de no-pensamiento ratificada por un modelo restrictivamente normativo, un modelo que necesita un mapa de realidad capaz de asegurar el juicio, incluso si el mapa es claramente falso; se trata de una forma de juicio que falsifica el mundo con objeto de apuntalar el juicio moral propiamente dicho como signo de cierto privilegio y de cierta «perspicacia» cultural, una manera de mantener a raya a las hordas (lo que, presumiblemente, no sólo incluiría a los no europeos sino, también, a los comparatistas 
complejidad del asunto en cuestión, consideramos importante pensar este antagonismo entre lo que hay y lo que viene ofreciendo una caracterización que ilustre de manera inacabada, pero aproximada, el argumento sobre un Sujeto ya (previamente) reconocido y otro por-venir, en medio de la escena educativa que se repite o que acontece como novedad radical e irrumpe habitando subversivamente el espacio-tiempo entre lo que hay y lo que viene.

\section{Del Sujeto que hay al sujeto que viene...}

Como hombre práctico que era, el Adelantado evitaba pérdidas de tiempo enviando el requerimiento por delante de sí y de su hueste. Se le explicaba el contenido del documento a unos indios que estuviesen a mano y se les mandaba a explicarlo, con suficientes días de anticipación, a los indígenas de los pueblos a donde tendría que llegar la expedición en su itinerario. Había habido tiempo para entenderlo, para reflexionar y decidirse, y el conquistador podía atacar inmediatamente a su llegada. (...) De más está decir que este macabro truco legal sirvió en todas partes, no solamente en Guatemala, para encubrir violaciones y ruina para los nativos. Hubo ocasiones en que se leyó desde lo alto de una colina, a distancia en que los indígenas no podían siquiera escucharlo, no digamos ya entenderlo. Otras veces se leyó a gritos mientras los indios huían por los montes. Hubo también ocasión en que se leyó desde la cubierta de un navío, antes de desembarcar a hacer redadas de esclavos. Con sobrada razón exclamaba Fray Bartolomé de las Casas que no sabía si reír o llorar al leer aquella ensarta de absurdideces teológicas destinadas a legalizar la esclavitud.

(Severo Maartínez Peláez, La patria del criollo. Ensayo de interpretación de la realidad colonial guatemalteca).

Podríamos pensar, a propósito de la escena que nos convoca y provoca, que la instrumentalidad del "hombre práctico" ha buscado también ahorrarse tiempos de encuentros y actuar de antemano, tal como se expresa en el fragmentado citado a comienzo de esta sección, desde lo que podríamos llamar el lado B de El Requerimiento. Así, podríamos seguir profundizando la traducción pedagógica de las memorias de la conquista y ver cómo la colonialidad del poder (o "colonialismo sin colonias", al decir de Mignolo) se replica -o repite- en nuestros espacios educativos. Evitar pérdidas de tiempo (sobre todo de ese tiempo capitalista por excelencia: el del chronos, el tiempo utilitario), explicar y extender la lógica embrutecedora que hace de los Otros eternos réprobos desiguales, suelen ser herencias de una educación colonial que da como natural estos hechos que aún perduran.

de toda índole). De aquí que pensar la brecha o el antagonismo planteado entre lo que hay y lo que viene, a propósito del sujeto en la educación, no busca un modelo normativo o un mapeo de la realidad que asegure el juicio sino, antes bien, profundizar y problematizar algunas percepciones acerca de una contextualidad que privilegia a unos en detrimento de otros. 
Muchos insisten en que los conflictos ideológicos han concluido y que todo da lo mismo, como si una homogeneización obscena hiciera de las diferencias y los antagonismos irresolubles meros matices integrables o incluibles en una gran máquina de impostura que funciona al ritmo de la "inevitable" gestión de "lo que hay". En nombre de esto, la forma democrática del capitalismo contemporáneo ha impuesto la "ley del número" que legisla que todo debe ser contabilizado: de este modo, los sujetos y sus procesos devienen números manipulables, la alteridad se reduce a la cifra y todo lo que cuenta mal o no cuente será reducido a lo mismo por equivalencia despreciativa. Este orden que da lugar a muros, controles, discriminación o desprecio por los otros, tiembla ante la irrupción de lo extraño que pone en juego todos los recursos de la estructura de normalidad -o institución- para intentar administrar su eventual inclusión o justificar su exclusión (Cerletti 2012). Al no poder dar cuenta de Todo, lo extraño marca el límite donde las experiencias o saberes propios no pueden reconducir o reelaborar su presencia en torno de (su integración o inclusión en) lo mismo. Ahora bien, la experiencia de la conquista y la colonialidad muestran la hostilidad de lo extraño, el genocidio del otro, la herida sensible frente a lo que viene de afuera o el extranjero. La educación colonial pareciera haber sido forjada al calor de estos traumas que se repiten a otras escalas mediante diferentes lógicas en la actualidad. De modo que en el marco educativo actual hay una tensión irreductible entre el reconocido Sujeto que hay y el desconocido sujeto que viene... La educación moderna/colonial, en la cual nos hemos formado, se nutre de la certeza objetivista que ahorra cualquier posibilidad de encuentro, que evita el azar o desprecia cualquier posibilidad igualitaria de conversación educativa. Se privilegia un sujeto previo, determinado por ciertos objetivos o parámetros de normalidad, que se muestra único, sólido, consistente en sí mismo y no se deja interpelar porque se pretende incontestable. El Sujeto que hay, en su afán de dominio, de control, de cálculo y de totalidad es hostil frente a lo extraño, de modo que cada una de las singularidades quedan tragadas en la desnudez de una masa sin atributos. Su lenguaje se pretende globalizador y único, atenido a "la realidad", le basta con ordenar desde la prepotencia de quien todo lo sabe: organiza y decide ateniéndose al principio del Todo es posible. No puede entenderse a sí mismo más que estableciendo relaciones cognitivas y reduciendo la importancia del pasado en el afán resultadista del aquí-ahora. Lo que se le resista será motivo de control, disciplinamiento, sanción, sojuzgamiento o evaluación, incluso indiferencia.

El sujeto (pedagógico o educativo) que viene, por el contrario, es un enigma a reconocer éticamente pero no a resolver. Tampoco un enigma que resulta en colonizador como pasó con los portadores del Requerimiento, sino un enigma singular portador de lo múltiple. Quizá lo innombrable o indefinible por lo 
colectivo que lo constituye, aunque inherentemente frágil por su desnudez de palabra. De lenguaje breve, ante el mandamiento de objetividad preferiría no hacerlo. Todo lo ignora, y bebe de esta fuente inagotable de deseo para caminar por los senderos de lo improbable. Está en busca del tiempo perdido y no reniega del pasado, sino que busca allí sus verdades impasibles. Lo imposible le seduce tanto como cualquier signo de alteridad e igualdad, para el sujeto que viene resistir es re-existir. Se desvía de los caminos trazados de antemano, descree profundamente de las chismosas evaluaciones y de las asesinas pedagogías del juicio.

El anterior planteo intenta romper con la idea de porvenir como resultado, fundamentalmente en relación al sujeto pedagógico o, mejor dicho, al sujeto en la educación. Pues si bien generalmente se lo ha pensado como previo u ontológicamente dado, o como un sujeto a formar en base a determinados criterios técnicos y objetivos curriculares, aquí se lo intenta pensar como un sujeto abierto a la contingencia singular e histórica que reniega del control resultadista al cual se lo somete habitualmente en el campo específico de la educación. Su alteridad radica en la existencia de una dimensión del sujeto que no puede ser gobernada por ninguna regla y/o no se adapta a la normas sociales fácilmente, esa no adaptabilidad es elemental porque permite pensarnos en direcciones inesperadas, tal como lo afirmó Butler en una conversación reciente (Giuliano 2017: 176-177). En dicha conversación dice, entre otras cosas, que siempre que la educación se suponga productora de resultados, los docentes se ven obligados a trabajar en una lógica productora de resultados esperados que descuida la experiencia y vivencia de sujetos. Con esto invita a pensar la educación en lógicas de deseo que no pueden ser reguladas y habla de la idea de experimentación como ese trabajar con y contra la función de vigilancia de las normas tentando y arriesgando los límites que operan a través y más allá de ellas. Esto implica en la formación no una mera repetición continua de las normas sino una repetición como una experimentación que incluye saber acerca de ellas aunque no implique estrictamente su obediencia.

Ahora bien, sabemos que la educación que heredamos de la modernidad/ colonialidad sigue dominando la escena pedagógica (probablemente, entre otras cosas, repitiendo de modos diversos la mencionada escena fundante) y si bien posee grietas o hendijas por donde podría acontecer el sujeto que viene frente al Sujeto que hay, el panorama indica que la apuesta está no sólo en ir a la escuela a habitarla sin más sino en ir a hacer escuela en ella. Y hete ahí la importancia radical de otros modos de vinculación o la búsqueda de formas de re-existencia pedagógica como entre o entridad que habita en medio de lo que hay y lo que viene. En esa línea, Lidia Rodriguez (2013) sostiene que una educación popular alternativa organiza un vínculo pedagógico basado en una igualdad radical, que es considerada un a priori y no un resultado del 
trabajo pedagógico. Exploraremos a continuación dicho postulado, pensando las implicancias que tendría para la posición del Maestro con las orientaciones que el pedagogo Simón Rodriguez y el filósofo Jacques Rancière podrían establecer.

\title{
De un Maestro popular a otro igualador: notas filosóficas para hacer (otra) escuela entre Simón Rodriguez y Jacques Rancière
}

\author{
El que no hace, nunca yerra: más vale errar que dormir. \\ Simón Rodriguez, Sociedades americanas. \\ Maestro es quien mantiene a quien busca en su camino, en donde él es el único \\ que busca y no deja de buscar. \\ Jacques Rancière, El maestro ignorante.
}

Dice Simón Rodriguez (1990) que no hace lo que ve hacer a todos: porque no es mono para imitar sin crítica ni veleta para volverse a todos los vientos; y que si todos pensaran como él, no habría Amos porque no habría Esclavos - ni títeres porque no habría quien los hiciese bailar - ni guerras, porque no habría a quien arrear al matadero. Pero cuando obedecer ciegamente es el principio que gobierna, hay tantos esclavos que es Amo el primero que quiere serlo y no hay pensamiento que resista a la incontestable prueba numérica del "todos lo hacen".

Mirar el suelo que se pisa, no esperar que el Olmo dé peras, contar con lo que uno tiene y no con lo que promete quien no tiene qué dar, son algunos principios que promovía don Simón. Desde allí pensaba que el Maestro tenía que ser elegido por aptitudes tales como ser dueño de la materia que promete enseñar, conocer el arte de enseñar que consiste en saber llamar, captar y fijar la atención, genio para insinuarse e ingenio para crearse medios de conseguir los fines que se propone en cada (ramo de) enseñanza. Distinguía tres tipos de docentes:

I. Los que ostentan sabiduría y no enseñan.

II. Los que quieren enseñar tanto que confunden a sus estudiantes.

III.Los que se ponen al alcance de todos, consultando sus capacidades.

Sostenía que los últimos serán los recordados, por ser maestros de verdad. Los otros podrían ser grandes profesores (especialistas en algo) o catedráticos (que enseñan desde lo alto), pero no maestros. Maestro es -para S. Rodriguezel que, transmitiendo sus conocimientos, con gusto ayuda a estudiar; enseña a aprender facilitando el trabajo, inspira en unos y excita en otros el deseo de 
saber. Vale repetirlo: enseña a aprender; no manda a aprender ni indica lo que se ha de aprender. De este modo, sigue enseñando luego virtualmente todo lo que se aprenda después porque su enseñanza influye en los demás estudios. Se trata de un maestro emancipador que da tiempo de ocio, reposo o descanso (eso significó Escuela en su origen) porque el estudio pide tranquilidad para contraerse mentalmente a observar las calidades y propiedades de las cosas y a pensar en los efectos y consecuencias de las acciones; enseña a ser preguntón para que, pidiendo el por qué, de lo que se mande a hacer, no se acostumbren a obedecer sin más; en la ignorancia misma halla el amor propio una ventaja y dice: "no es necesario ser sabio para saber: yo sé sin haber aprendido" (Rodriguez 1990). Un Maestro, como don Simón, prefiere errar que dormir.

Como podrá observarse, Simón Rodriguez no sólo fue un Maestro de la educación popular sino también un emancipador que enseñaba a aprender pero no mandaba ni indicaba lo que se "debiera" aprender, transmitía un deseo (de saber) y ayudaba a estudiar de modo que su enseñanza resonaba en próximos estudios (lo que encuentra cierta similitud con el método de Jacotot). Esto invita a que pensemos junto a otro igualador popular (igualdad que nada tiene que ver con la homogeneización), una singularidad doble desde el punto de vista en que la posición de Jacques Rancière (2007) se alimenta de la experiencia y lo escrito por el pedagogo francés Joseph Jacotot (también en el siglo XIX como don Simón). Por él sabemos que la igualdad como objetivo a alcanzar en medio de la desigualdad, la aplaza al infinito; ella nunca viene después, no puede ser resultado sino punto de partida. De este modo, educar puede confirmar una incapacidad en el acto mismo que pretende reducirla o forzar una capacidad, que se ignora o se niega, a reconocerse y a desarrollar con todas las consecuencias de este reconocimiento (Rancière 2007: 9). Así, las amistades de la igualdad no tienen que educar al pueblo para acercarlo a la igualdad, sino emancipar las inteligencias: invitar a todas y cada uno a verificar la igualdad de las inteligencias. A quienes insisten en la mentira de la igualdad de oportunidades, habría que mostrarles que el saber no conlleva en sí mismo ninguna consecuencia igualitaria. Tal como enseñaba Jacotot, la igualdad no es ni formal ni real, no consiste ni en la enseñanza uniforme ni en la disponibilidad de productos a bajo precio; la igualdad es fundamental y ausente, es actual e intempestiva, siempre atribuida a la iniciativa de los individuos y de grupos que, contra el curso ordinario de las cosas, asumen el riesgo de verificarla (Rancière 2007: 13).

Como cuenta Rancière, el acto esencial del maestro era (y sigue siendo en muchos casos si no en la mayoría) explicar (para que otros comprendan), poner en evidencia los elementos simples de los conocimientos y hacer concordar su simplicidad de principio con la simplicidad de hecho que caracterizaría a los espíritus jóvenes e ignorantes; enseñar deviene, así, en transmitir conocimientos 
y formar los espíritus, conduciéndolos, según un orden progresivo, de lo más simple a lo más complejo. Pero una paradoja entre el maestro y la palabra se sitúa al nivel del aprendizaje: pues lo que mejor aprende alguien, aquello cuyo sentido capta mejor y se lo apropia para hacer uso personal de ello, se hace sin maestro explicador. Coincidimos con Rancière (2007: 20) en que el mejor ejemplo podría ser la lengua materna, que da prueba del rendimiento desigual de los aprendizajes intelectuales (acontecidos sin ningún maestro explicador) basados en la escucha y la retención, la imitación y repetición, la equivocación y la corrección propia, la casualidad y cierto método.

En el orden explicador, nadie comprende sin la explicación de un maestro: el otro es siempre un incapaz, constituido por la explicación de un explicador que necesita de él para seguir explicando. De alguna manera, ambos se constituyen en un movimiento que hace dialogar la explicación iluminada de uno con el silencio incompetente del otro. Tal como lo afirma Rancière, explicar algo a alguien es, en primer lugar, demostrarle que no puede comprenderlo por sí mismo. Siguiendo este planteo, el truco característico del explicador consiste en un doble gesto:

-decretar el comienzo absoluto: momento determinado para iniciar el acto de aprender.

-arrojar un velo de ignorancia sobre todas las cosas a aprender, para luego él mismo encargarse de levantarlo.

Dicha gestualidad sigue el principio del embrutecimiento, un mito pedagógico que divide al mundo en dos: sapientes e ignorantes, inteligencias superiores e inferiores, iluminados y réprobos. De este modo los metodistas, didactas y progresistas se preocupan en buscar las mejores maneras de hacer(se) comprender, es decir, perfeccionar el progreso en el embrutecimiento. Por el contrario, y considerando a Jacotot, comprender es traducir en tanto podemos ofrecer el equivalente de un texto y no su razón: más allá de los textos habita la voluntad de expresión, de interpretación, de traducción. Los metodistas o didactas, amantes de los procedimientos razonados (inherentes a la razón, más tarde evaluadora) detestan el azar, olvidan que aprendizaje y azar van de la mano. Así, muchas veces, cuando no todas, aprender es observar y retener, repetir y verificar, relacionar lo que se busca conocer con lo ya conocido, hacer y reflexionar sobre lo hecho. Todo lo que ocurre al menos una vez puede repetirse siempre, dice Rancière. Aprender habita la tensión del deseo propio o la exigencia de una situación, no el embrutecimiento que subordina unas inteligencias a otras. Rancière utiliza el término voluntad, pero en el fondo se trata del deseo ${ }^{7}$ : una relación deseo a deseo e inteligencia a inteligencia, en la

${ }^{7}$ Rancière (2007: 75) utiliza originalmente el término "voluntad" como el poder de moverse y Araucaria. Revista Iberoamericana de Filosofia, Política y Humanidades, año 19, n 38 . Segundo semestre de 2017. Pp. 265-284. ISSN 1575-6823 e-ISSN 2340-2199 doi: 10.12795/araucaria.2017.i38.12 
cual el camino emancipador se atraviesa en medio de la diferencia mantenida entre estas dos relaciones. De este modo, se llamará emancipación al acto de una inteligencia que no obedece más que a sí misma, aun cuando el deseo obedece a otro deseo.

Aprendizajes sin explicación: hemos aprendido muchas cosas sin que nos las explicaran, por ello quien emancipa no tiene que preocuparse por lo que el emancipado debe aprender. Aprenderá lo que quiera, tal vez nada, pero sabrá que puede aprender porque la misma inteligencia está obrando en las todas producciones del arte humano (Ranciére 2007: 33-34). Cualquiera tiene la misma inteligencia que cualquiera, es un principio a partir del cual se puede aprender cualquier cosa y relacionar todo el resto con ella: esta podría ser una enseñanza ética primera.

\section{In-conclusión: el reconocimiento ético como acto educativo.}

Hemos tomado una escena histórica, pasada por alto muchas veces o reprimida muchas otras, para pensar su retorno sintomático en medio de la educación contemporánea. Dicho inicio invitó a adentrarnos en la discusión sobre el sujeto (que encarna el síntoma) en la educación, a la vez que problematizamos -desde diferentes perspectivas filosóficas- algunas concepciones en torno del llamado sujeto pedagógico. Esto nos llevó a pensar la tensión entre un sujeto reconocido de lo que hay y lo desconocido de un sujeto que viene o puede advenir, y el hecho de que puede o pueda advenir nos introduce en el campo de (im)posibilidades propias de la educación que involucra diferentes formas de existencia o re-existencia pedagógica donde se ponen en juego principios que pueden subvertir las reglas de dicho campo específico. Ejemplos éticos e históricos de esto han sido las posiciones de Maestros como Simón Rodriguez o Joseph Jacotot, a los que recurrimos para explorar gestualidades éticopedagógicas que subviertan los contornos de lo posible y lo imposible en un espacio-tiempo educativo habilitante de otros modos de relación o vinculación ética-política. Pero si la escena sigue servida o se repite y los sujetos "no saben,

actuar según el movimiento propio de la inteligencia antes que ser una instancia de elección. Pero por Deleuze sabemos que la aventura de lo involuntario se encuentra a nivel de cada facultad; los signos sensibles nos fuerzan a buscar la verdad y con ello movilizan una memoria involuntaria (o una imaginación involuntaria nacida del deseo), desencadenan en el pensamiento lo que menos depende de su buena voluntad: el propio acto de pensar (Deleuze 1995: 181-183). De aquí que el deseo no sólo se aleja de los ecos voluntaristas y pone en juego dimensiones corporales que se escapan a la mera conciencia del sujeto, sino que permite pensar facultades como la inteligencia, la memoria o la imaginación, en sus formas involuntarias que permiten descubrir y alcanzar su propio límite a partir de lo que sólo ellas pueden interpretar. Así también, Rancière (2007: 87) concibe la voluntad como ese deseo de comprender y hacerse comprender sin el cual nadie podría jamás dar sentido a las materialidades del lenguaje: no se trata del irrisorio poder de levantar el velo de las cosas, sino de la potencia de traducción que confronta a un orador con otro.

Araucaria. Revista Iberoamericana de Filosofía, Política y Humanidades, año 19, n 38. Segundo semestre de 2017. Pp. 265-284. ISSN 1575-6823 e-ISSN 2340-2199 doi: 10.12795/araucaria.2017.i38.12 
pero lo hacen", hay todo un "marco" en el que se enmarca dicha escena y el cual posibilita reconocer a los sujetos que la habitan al tiempo que desconoce a otros u otros quedan excluidos de tal "marco" interpretativo. Aquí entran en juego mecanismos, dispositivos, tecnologías productoras de desigualdad que devalúan toda alteridad y se ven condensadas - o comandadas- por una razón evaluadora como tipo de racionalidad que impele a medir, comparar y normalizar a sujetos tan singulares como diferentes, al mismo tiempo que opera en su acción un principio de clasificación en función de un ideal de sujeto o "sujeto ideal" (¿quizá trascendental?). Esta operación indica la proximidad o lejanía de las subjetividades respecto de la norma que reconoce e incluye como "sujetos aprobados" a quienes se acercan al ideal de sujeto establecido, mientras que excluye del marco de reconocimiento a todo desaprobado que se aleja de lo esperable por la normalidad. Dicha cuestión pone en tensión las posibilidades e imposibilidades de acontecimientos, de novedades radicales y subversiones de lo posible en el campo específico de la educación que hace tanto tiempo muchos especialistas insisten en transformarlo en un campo específico de evaluación (tan similar, fundamentalmente en su olvido ético, a un campo de concentración). Por ello resulta importante el hecho de no presuponer un sujeto a toda pedagogía, así como también visualizar las operaciones de poder que reconocen a determinados sujetos en la educación en detrimento de otros. Más allá y más acá de lo que entendamos por sujeto pedagógico o sujeto en la educación, se hace necesario preguntarse por los dispositivos, mecanismos o tecnologías que los re-conocen como tales y preguntarse también sobre las gestualidades de reconocimiento ético en la educación. Podría decirse que la racionalidad evaluadora busca re-conocer a los sujetos, busca llegar a las profundidades insospechadas de la subjetividad mediante todo tipo de estrategias. Por el contrario, encontramos en gestualidades como las de Simón Rodriguez o Joseph Jacotot una preocupación ética sobre la vinculación con los otros en tanto sujetos de un encuentro pedagógico-educativo en medio de un deseo (quizá) compartido. Observamos entonces que el lugar del otro o el espacio-tiempo que se le convida o en el marco del cual nos encontramos con otros varía en forma notable en la escena de la que partimos y en las escenas que buscan hacer (otra) escuela.

Los marcos mediante los cuales aprendemos, o no conseguimos aprender, están políticamente saturados. La capacidad epistémica involucrada en el acto de aprender es parcialmente dependiente de unas normas que intentan definir (explícita o implícitamente) lo que es el aprendizaje, como si fuera una cuestión claramente ontológica y no primordialmente ética. De esta manera se pone en juego un dilema entre la producción normativa de una ontología y el problema ético del reconocimiento. En medio de ello se ubica la subjetividad y la alteridad, de modo que si se tiene claro lo que es el aprendizaje también se presupondrá 
claro al sujeto que lo encarna, y la caracterización aproximativa llevada a cabo más arriba respecto de un desconocido sujeto por-venir se reduce al sujeto (previo) que hay. Y, como ya dijimos, no se trata de encasillar a unos en un lado y a otros en otro, sino de visualizar que el problema no es meramente cómo incluir a más personas dentro de las normas ya existentes, sino considerar cómo las normas ya existentes asignan reconocimiento de manera diferencial (Butler 2010: 20). De este modo entran en juego los marcos (evaluativos-normativos) que operan para diferenciar aquellas subjetividades que "aprenden" o "pueden aprender" de aquellas que "no aprenden" o "no pudieron aprender" y que generan ontologías específicas del sujeto. Butler (2010: 17) sostiene que los sujetos se constituyen mediante normas que, en su reiteración, producen y cambian los términos mediante los cuales se reconocen. Entonces, aprender el reconocimiento ético o reconocer éticamente el aprender (y, por tanto, también el sujeto) probablemente esté íntimamente relacionado con lo impreciso de una huella asociada al sentir y el percibir aunque no siempre -o todavía- a una manera conceptual de conocimiento que suele implicar la (imposible) fiabilidad anticipatoria de algún resultado. Como observamos:

El problema no es meramente o sólo "ontológico", puesto que las formas que toma el sujeto, así como los mundos cotidianos que no se conforman a las categorías disponibles del sujeto, surgen a la luz de los movimientos históricos y geopolíticos. (...) Si nuestros marcos normativos presuponen que estos rasgos ostensiblemente definidores de sujetos singularmente determinados son sus propios objetos, entonces el reconocimiento se convierte en parte de esa misma práctica de ordenar y regular a los sujetos según unas normas preestablecidas (Butler 2010: 193-196).

Si Butler está en lo cierto al afirmar que cada caso normativo está sombreado por su propio fracaso, y de cuando en cuando este fracaso adopta una forma figural, estar "enmarcado" puede significar ser objeto de una artimaña o ser incriminado falsa o fraudelentamente con pruebas inventadas (como evaluaciones) que, al final, acaban "demostrando" la culpabilidad del sujeto. Así actúa de hecho la razón evaluadora y su obsesión por incluir -y reducir- a cada alteridad en su marco. Pero el marco nunca determina del todo eso que percibimos, pensamos, reconocemos y aprendemos: "algo excede al marco que perturba nuestro sentido de la realidad; o, dicho con otras palabras, algo ocurre que no se conforma con nuestra establecida comprensión de las cosas" (Butler 2010: 24). Siguiendo este planteo, lo que "se escapa de las manos" es, precisamente lo que rompe con el contexto que enmarca el acontecimiento, como a una terceridad que incomoda todo marco binario le acompaña la alteridad que anuda lo Real, lo imaginario y lo simbólico en todo planteo educativo. 
Una vez que empezamos a pensar críticamente sobre los esquemas de evaluación y comparación de sujetos, más se dificulta re-abordar una política del juicio y de la evaluación aun viviendo en una época cuyo mandato socioeducativo pareciera ser sólo y siempre juzgar.

Porque el reconocimiento ético va de la mano con postular una igualdad radical o aprender la igualdad en medio de nuestra fragilidad constitutiva. Así, cuando el mero re-conocer induce a valorar un sujeto a expensas del otro o hacer del otro un mero objeto a devaluar (porque toda evaluación del otro es una devaluación de su alteridad), el reconocimiento ético deviene un acto educativo cuando cede a los lazos que nos atan y desatan, registran y exigen la igualdad afectivamente. Es, incluso, un modo de re-existencia pedagógica, especialmente cuando rechaza y rompe los marcos mediante los cuales se forja la razón evaluadora una y otra vez.

Postular una igualdad radical, que implica también deshacerse o al menos eludir las lógicas (d)evaluativas de la alteridad, nos involucra entonces en un verdadero acto educativo. Abrevando en la noción lacaniana de acto psicoanalítico ${ }^{8}$ que toca la dimensión de algún Real imposible (como podría ser la educación, recordemos lo que decía Freud sobre ella reconociéndola como una de las tareas imposibles), podríamos concebir al acto educativo como un gesto ético-pedagógico que subvierte el principio estructurante de su propio campo de (im)posibilidades. Es decir, junto con el antecedente del mero intento de "resolver una variedad de problemas parciales" dentro del campo pedagógico, un acto educativo redefine los contornos mismos de lo que es posible y, por ello, parece ser imposible dentro del universo simbólico dado pero cambia sus condiciones de manera que crea retroactivamente las condiciones de su propia posibilidad (Žižek 2011: 132). En efecto, no ocurre dentro del horizonte dado de lo que parece ser posible, sino que da pie a experienciar de cuerpo presente aquel señalamiento de un mudo Lacan que igual decía: lo imposible sucede. Si el mundo pedagógico de lo posible devino en la fábula desigualitaria que hoy nos tiene a todas y todos en estado de "evaluación permanente", habrá que recurrir al clásico dicho y repetir -no sin diferencias-: ¡seamos realistas, hagamos lo imposible!

8 "En suma, un acto auténtico no es simplemente externo con respecto al campo simbólico hegemónico alterado por él: un acto es un acto sólo con respecto a algún campo simbólico, como una intervención en él. Es decir: un campo simbólico está siempre y por definición en sí mismo 'descentrado', estructurado alrededor de un vacío/imposibilidad central (una narrativa de vida personal, digamos, es un bricolage de intentos finalmente fallidos por reconciliarse con algún trauma; un edificio social es un intento finalmente fallido por desplazar/oscurecer su antagonismo constitutivo). Un acto altera el campo simbólico en el cual interviene no desde ninguna parte, sino precisamente desde el punto de vista de su imposibilidad intrínseca, el obstáculo que es su principio estructurante repudiado oculto" (Žižek 2011: 136). 


\section{Referencias bibliográficas:}

Buenfil Burgos, R. N. (1996). Revolución mexicana, mística y educación. México: Ed. Torres.

Butler, J. (2010). Marcos de guerra. Las vidas lloradas. México: Paidós.

Butler, J. (2011 [2003]). "Universalidades en competencia" en: Butler, J., Laclau, E., Žižek, S. Contingencia, hegemonía, universalidad: diálogos contemporáneos en la izquierda. Buenos Aires: Fondo de Cultura Económica.

Cerletti, A. (2008). Repetición, novedad y sujeto en la educación: un enfoque filosófico y político. Buenos Aires: Del Estante Editorial.

Cerletti, A. (2013). Identidad, igualdad y educación. Praxis \& Saber, 4(7), 1733. Recuperado de: http://revistas.uptc.edu.co/index.php/praxis_saber/ article/view/2046/2047

Deleuze, G. (1995). Proust y los signos. Barcelona: Editorial Anagrama.

Giuliano, F. (2017). Rebeliones éticas, palabras comunes. Conversaciones (filosóficas, políticas, educativas) con Judith Butler, Raúl FornetBetancourt, Walter Mignolo, Jacques Rancière, Slavoj Žižek. Buenos Aires: Miño y Dávila Editores.

Laclau, E. y Mouffe, C. (2010 [1985]). Hegemonía y estrategia socialista: hacia una radicalización de la democracia. Buenos Aires: Fondo de Cultura Económica.

Mignolo, W. (2007). La idea de América Latina. Barcelona: Gedisa.

Puiggrós, A. (1996). "Presencias y ausencias en la historiografía pedagógica latinoamericana", en: Cucuzza, Héctor Rubén (comp.) Historia de la Educación en Debate. Buenos Aires: Miño y Dávila Editores.

Puiggrós, A. (2006). Historia de la educación argentina: tomo 1: sujetos, disciplinas y currículum en los orígenes del sistema educativo argentino (1885-1916). Buenos Aires: Galerna.

Rancière, J.(2007). Elmaestro ignorante: cincolecciones sobre la emancipación intelectual. Buenos Aires: Libros del Zorzal.

Rodriguez, L. (2013). "La elección categorial: alternativas y educación popular", en Educación popular en la historia reciente en Argentina y América Latina. Aportes para balance y prospectiva. Buenos Aires: APPEAL. Recuperdado de: http://appeal.com.ar/wp-content/uploads/2015/10/ LIBRO-APPEAL-2013.pdf

Rodriguez, S. (1990). Sociedades americanas. Caracas: Biblioteca Ayacucho. Žižek, S. (2009 [1989]). El sublime objeto de la ideología. Buenos Aires: Siglo XXI Editores. 
Žižek, S. (2011 [2003]). “¿Posmodernismo o lucha de clases? ¡Sí, por favor!” en: Butler, J., Laclau, E., Žižek, S. Contingencia, hegemonía, universalidad: diálogos contemporáneos en la izquierda. Buenos Aires: Fondo de Cultura Económica. 